\title{
LEI ANTITERRORISMO E RESTRIÇÃO DA AÇÃO POLÍTICA: DISSIDÊNCIA E RESISTÊNCIA EM TEMPOS DE CRISE DA REPUBLICA ${ }^{1}$
}

\author{
Mariana de Mattos Rubiano²
}

Resumo: Este artigo visa discutir a lei $\mathrm{n}^{\circ} 13.260$ de 2016, mais conhecida como lei antiterrorismo, levando em consideração o pensamento de Hannah Arendt. Especificamente, procuraremos refletir sobre as consequências desta lei nas atividades públicas no Brasil por meio das categorias arendtianas, tais como política, ação, desobediência civil, dissidência, pluralidade e poder.

Palavras-chave: Hannah Arendt - política - dissidência - desobediência civil - direitos.

\section{Introdução}

O livro Crises da República, de Hannah Arendt, é particularmente interessante em nosso contexto, pois seus ensaios tratam, em geral, da redução do espaço público político nos EUA na década de 1960. A autora nesta obra não trata do modo de dominação nos regimes totalitários, na tirania ou na ditadura, como fez em outros textos. Mas aponta os empecilhos para a liberdade e a ação política no sistema representativo liberal, mostra como um regime considerado republicano e democrático pode restringir a participação política, reduzir direitos e interditar a luta por novos direitos. Além disso, ela indica no artigo intitulado "Desobediência civil" que tipo de ação pode fortalecer a vida política e a liberdade no sistema representativo.

Especificamente, os conceitos de dissidência, resistência, poder, liberdade e ação são importantes para nos auxiliar na reflexão do presente. Eles são capazes de iluminar alguns problemas políticos ao indicar os obstáculos que a ação livre encontra na contemporaneidade e ao apontar para o tipo de ação que pode revigorar o espaço público. ${ }^{3}$

Levando isto em consideração, este trabalho visa refletir sobre o impacto da aprovação da lei no 13.260 em março de 2016, conhecida como lei antiterrorismo, a partir

\footnotetext{
${ }^{1}$ Gostaria de agradecer aos amigos Thiago Dias, Rodrigo Souza e Alessandra Tsuji que me incentivaram a pensar sobre o tema tratado neste artigo. A partir de uma conversa com eles, comecei a ler sobre a lei antiterrorismo e desenvolvi um pouco a reflexão sobre o assunto no X Encontro Internacional Hannah Arendt, na UFG, e na II Jornada de Ética e Filosofia Política, na USP.

${ }^{2}$ Doutora em Filosofia pela USP.

${ }^{3}$ Concordamos com Correia em que o pensamento de Arendt conserva seu vigor no que concerne a crítica da valorização do trabalho e da vida como bem supremo e em sua defesa da dignidade da atividade política. Conferir em Hannah Arendt e a Modernidade, p. XXX.
} 
de alguns conceitos arendtianos. Para tanto, em um primeiro momento apresentaremos brevemente a definição de ação, desobediência civil, resistência e poder, para, em um segundo momento, discutir sobre os efeitos políticos da aprovação desta lei. ${ }^{4}$

Para Arendt, a ação política consiste no debate, na deliberação e na ação em conjunto os quais definem os rumos do mundo. $\mathrm{O}$ mundo não corresponde a Terra ou ao domínio natural, ao contrário, está ligado ao artifício: é feito e permeado por coisas, histórias e feitos humanos. O mundo se torna assunto das pessoas na medida em que pode abrigá-las ou desampará-las, permitir ou interditar modos de relacionamento entre elas. ${ }^{5}$ Por ser comum, dizer respeito a muitos, o mundo não pode ser conservado ou mudado pelo esforço de um só, é preciso que muitos se engajem na ação para intervir nele. Nesse sentido, de acordo com a autora, por definição, a atividade política envolve uma pluralidade de agentes. ${ }^{6}$

Além disso, ela afirma que somente na ação é possível experimentar a liberdade em sentido pleno. A liberdade política significa o direito de participar do governo, de tomar parte nos assuntos que dizem respeito a toda comunidade. ${ }^{7}$ A liberdade não se encontra no interior do sujeito, ela só pode ser uma realidade concreta no espaço público, pois somente no relacionamento com outros é possível tomar consciência da liberdade ou de sua ausência. Levando isso em conta, vemos que para Arendt a atividade política não pode ficar restrita ao voto e ao governo representativo.

As cabines em que depositamos as cédulas são, sem sombra de dúvida, muito pequenas, pois só têm lugar para um. Os partidos são completamente impróprios; lá somos, quase todos nós, nada mais que o eleitorado manipulado. ${ }^{8}$

\footnotetext{
${ }^{4}$ Nesse sentido, embora "Desobediência civil" seja a principal referência teórica aqui, o presente artigo não procurará comentá-lo detidamente. Nosso objetivo consiste em fazer o que Arendt chama de exercício de pensamento. Trata-se de uma reflexão que emerge da concretude dos acontecimentos políticos e busca compreender o que está em jogo: indagar quais elementos ameaçam a vida política e quais intervenções são promissoras.

${ }^{5}$ Sobre mundo e espaço público ver em $A$ Condição Humana, p. 61-65.

${ }^{6}$ Conferir em $A$ Condição Humana, p. 8 e 9.

${ }^{7}$ Arendt afirma a íntima relação entre liberdade e política em diversos pontos de sua obra, ver, por exemplo, em Entre o Passado e o Futuro, p. 192 e 197; Sobre a Revolução, p. 58 e 278. Da mesma forma, a autora reiteradamente aponta que é preciso um espaço publicamente organizado para que a liberdade possa ser experimentada. Conferir em Entre o Passado e o Futuro, p. 194 e Sobre a Revolução, p. 59.

${ }^{8}$ Crises da República, p. 200.
} 
A autora ainda sustenta que, para qualquer governo ou instituição ser dotado de poder, eles precisam mais do que voto. Poder, segundo Arendt, consiste no potencial de realizar algo no mundo graças ao apoio de um grupo que sustenta um ato. Sua condição de existência é o espaço público onde os homens possam se inter-relacionar por meio do discurso e da ação. Assim, o poder requer agentes livres que se engajam em um empreendimento comum. Nesse sentido, ele é oposto à obediência gerada por coação, por ameaça ou emprego de violência.'

Para que os atos de um governo sejam dotados de poder - isto é, sustentados pelo povo - é preciso a existência de espaços públicos que possibilitem a troca de opiniões entre os homens e que algumas instituições estejam abertas ao debate ampliado, isto é, que elas considerem a pluralidade das opiniões públicas. Dito de outra forma, as instituições precisam ser permeadas por manifestações populares tanto de apoio e assentimento quanto de protesto e dissidência.

Desse modo, Arendt relaciona o vigor da política e do corpo político com o espaço dado à dissidência. Um regime não tirânico implica essencialmente o apoio público e a possibilidade de divergência. Levando isso em conta, a autora defende que na Constituição dos EUA deveria estar inscrito não só os direitos de liberdade de expressão e de escrever petições ao governo, mas também o direito de associação e de dissidência. Com isso, o corpo político abrigaria a participação popular mais ampla, ou seja, a cidadania não poderia ser restrita ao voto, mas, principalmente, se daria por meio das manifestações nos espaços públicos. Nesta perspectiva, o direito de associação e de dissidência garantiria que as opiniões dos cidadãos fossem consideradas nos negócios diários do governo. ${ }^{10}$

Kalyvas enfatiza que o pensamento arendtiano explora tanto as tensões como as relações entre a política ordinária e a política extraordinária: o governo constitucional, a representação, as leis e as instituições devem conferir regularidade e estabilidade à comunidade política, mas não podem impedir a liberdade de ação e de associação do povo. Para ele, tradicionalmente, a política ordinária é monopolizada por elites políticas, partidos burocratizados, representação, eleição e rígidos procedimentos institucionais, por isso, é caracterizada pela baixa participação popular nos processos de decisão. Ao contrário, a política extraordinária e democrática geralmente é experimental e provisória, envolve alto grau de mobilização e a abertura de espaços públicos informais e não institucionalizados que desafiam o status quo e a autoridade pré-estabelecida. Nos momentos em que a política extraordinária emerge, são rearranjados as normas e valores fundamentais que regulam as instituições onde a política regular e ordinária se desenrola. ${ }^{11}$

\footnotetext{
${ }^{9}$ Ver em A Condição Humana, p. 249-251.

${ }^{10}$ Conferir em Crises da República, p. 74 e 75.

${ }^{11}$ Ver em Democracy and the Politics of the Extraordinary, p. 6-8.
} 
Arendt aponta que quando o espaço de debate e de contestação é reduzido, quando a pluralidade de opiniões é desconsiderada pelo governo, a desobediência civil se torna um importante modo de agir. De acordo com a autora, a desobediência civil acontece quando os canais regulares onde se podiam expressar queixas e opiniões dissidentes não funcionam. ${ }^{12}$ Em outras palavras, quando a divergência não pode se expressar por meios institucionais, quando as opiniões dissidentes são desprezadas, ela se torna desobediência civil, uma manifestação política extra institucional e extra legal.

Conforme Kalyvas, a desobediência civil consiste em uma manifestação política fluida que faz uma mediação entre a política regular e a extraordinária. A contestação civil é uma ação extra legal, fora das instituições, mas que visa uma mudança nas leis e nas instâncias governamentais. Nesse sentido, este tipo de ação é importante no pensamenro arendtiano na medida em que reafirma a ligação entre a política ordinária e a extraordinária. ${ }^{13}$

Arendt chama a atenção para o fato de que desobediência civil não é crime. $\mathrm{O}$ criminoso procura benefícios privados, privilégios e quando viola a lei, procura agir sem ser visto. Ao contrário, os contestadores civis desafiam a lei em nome de uma causa pública e de direitos e, por isso mesmo, procuram agir diante de todos. Desobediência civil geralmente é praticada por uma minoria que busca ou a preservação de algum direito ou estabelecer um novo direito. Assim, ela não visa benefícios privados uma vez que a contestação civil se refere a toda a comunidade.

Há um abismo de diferença entre o criminoso que evita os olhos do público e o contestador civil que toma a lei em suas próprias mãos em aberto desafio. A distinção entre a violação aberta da lei, executada em público, e a violação clandestina é tão claramente óbvia que só pode ser ignorada por preconceito ou má vontade. ${ }^{14}$

Com isso, a autora afirma que protestos contra atos de governo e leis, mesmo que envolvam a desobediência civil, são questões políticas. Eles não devem ser tratados como questões jurídicas e policiais, já que do ponto de vista jurídico não há diferença entre o criminoso e o contestador civil: ambos violam a lei e, por isso, devem ser perseguidos e penalizados. ${ }^{15}$ Apesar de entender que a contestação civil é uma forma de ação política, Arendt reconhece que tais manifestações são frequentemente tratadas por meio de instituições jurídicas e de forças policiais. Ela alerta que a repressão e a condenação da

\footnotetext{
12 Ver em Crises da República, p. 67.

${ }^{13}$ Ver em Democracy and the Politics of the Extraordinary, p. 284, 288 e 291.

14 Crises da República, p. 69.

15 Conferir em Crises da República, p. 67.
} 
contestação civil e de protestos acabam com a dissidência, com a pluralidade de opinião e, portanto, pode levar à tirania ou a uma ditadura.

\section{II}

Levando em consideração esta resumida apresentação dos conceitos mobilizados no ensaio intitulado "Desobediência civil", podemos refletir sobre o espaço dado ao debate público e à dissidência no Brasil. Infelizmente, o Estado brasileiro tem tratado manifestações de contestação pela via jurídica e policial, reduzindo as possibilidades de divergência e dissenso, levando movimentos sociais e minorias ou a recuar ou a recorrer à desobediência civil para que suas opiniões sejam consideradas. Ainda que o artigo $5^{\circ}$ da Constituição de 1988 abarque o direito de manifestação de pensamento, reunião e associação conferindo autoridade e legitimidade para a formação de grupos dissidentes e de expressão de seus pontos de vistas divergentes, nos últimos tempos vimos a recorrente criminalização de atos políticos e a repressão violenta de movimentos e manifestações reivindicatórios.

Desde 2013, a truculência policial contra manifestações populares vêm aumentando e as instituições governamentais se tornaram cada vez mais fechadas a certas reivindicações. De acordo com Edson Teles, 2013 foi um momento de virada, pois as forças de esquerda que ocupavam cargos no governo, no geral, calaram-se diante da repressão e não acolheram as demandas sobre passe livre e moradia que foram centrais nas jornadas de junho e no movimento "não vai ter copa". ${ }^{16}$ Para Negri, os quadros partidários da velha esquerda não compreenderam a ação das minorias em 2013 e 2014, eles deslegitimaram e abafaram tais manifestações receosos de que a emergência destes movimentos ameaçariam a governabilidade no plano federal. ${ }^{17}$

A violência como meio de silenciamento de reivindicações também foi usada contra as lutas por educação: os protestos dos professores no Paraná em 2015 e as ocupações nas escolas em Goiás, São Paulo, Rio de Janeiro e Paraná em 2016 foram duramente reprimidos.

O abafamento do dissenso por meio do uso da força em detrimento do debate ficou claro com a desocupação do Centro Paula Souza. O pedido de reintegração de posse desta escola foi deferido pelo juiz de primeira instância. No entanto, o juiz exigiu que a reintegração de posse fosse realizada sem uso de armas letais e não letais (ou melhor, armas menos letais), abrindo a possibilidade para uma desocupação negociada. Tal exigência foi

${ }^{16}$ Conferir em "Qual democracia?”, artigo publicado no bolg da Boitempo: https://blogdaboitempo.com.br/2016/03/18/qual-democracia-2/

${ }^{17}$ Ver em "Para onde vai o PT?". Acesso no site: http://outraspalavras.net/brasil/toni-negri-impressoes-deuma-visita-ao-brasil/ 
derrubada no dia seguinte no Tribunal de Justiça de São Paulo e a reintegração de posse foi feita com violência. Depois deste episódio, o secretário de segurança pública de São Paulo naquele momento, Alexandre de Moraes, defendeu a reintegração de posse sem a necessidade de mandado judicial. A Procuradoria Geral do Estado emitiu um parecer orientando a desocupação de prédios públicos sem recorrer à decisão judicial. ${ }^{18}$ Assim, o espaço de diálogo com movimentos reivindicatórios ficou ainda mais reduzido.

Tais práticas diante das manifestações políticas mostram que as instituições estatais não estão abertas ao debate e à negociação com minorias divergentes. Ao contrário, indicam claramente que os movimentos de contestação têm sido tratados pela via judicial e policial.

Além disso, em março de 2016, a lei no 13.260, conhecida como lei antiterrorismo, passou a restringir o direito de divergência inscrito na Constituição e criou apoio legal para a criminalização e repressão de manifestações de contestação civil. Em outras palavras, a lei antiterrorismo potencializou a capacidade do Estado brasileiro de perseguir e reprimir contestadores civis.

O projeto desta lei foi iniciativa do Executivo - assinado pelo então ministro da justiça, José Eduardo Cardoso - e tinha como objetivo dar uma resposta à pressão internacional e cumprir acordos firmados entre o Estado brasileiro e o Grupo de Ação Financeira (GAFI), que busca a combater a lavagem de dinheiro e o financiamento do terrorismo.

No projeto de lei havia uma preocupação de que o novo ordenamento jurídico não ferisse as garantias e direitos fundamentais, especificamente, que não restringisse a liberdade de manifestação e os movimentos reivindicatórios. Mas com a tramitação do projeto de lei no Congresso - composto por maioria conservadora - algumas mudanças sugeridas por deputados federais e senadores reforçaram o perigo de penalizar atos de contestação e de perseguir dissidentes.

Organizações de direitos humanos, desde o início, foram contrárias a este projeto de lei por dois motivos, a saber: em primeiro lugar, o Código Penal já previa muitas das condutas relacionadas com terrorismo. A lei antiterrorismo simplesmente aumenta a pena destas condutas. Isso não parece ser necessário ou efetivo para as organizações de direitos humanos uma vez que leis mais duras não tornaram nenhum país mais seguro contra este

\footnotetext{
${ }_{18}$ Este parecer argumentava que do mesmo modo que um cidadão privado pode defender sua propriedade sem necessidade de pedir autorização a um juiz, o Estado poderia defender a propriedade pública. Tal parecer despreza completamente a diferença entre a invasão de uma propriedade com objetivo criminoso e a ocupação de uma propriedade por motivo de demandas políticas e sociais. Além disso, negligencia a diferença de meios violentos à disposição de um indivíduo privado e dos mobilizados pelo Estado. Sobre parecer da Procuradoria Geral do Estado, ver em http://g1.globo.com/sao-paulo/noticia/2016/05/governo-alckminlibera-reintegracao-de-posse-sem-decisao-judicial.html
} 
tipo de crime. Em segundo lugar, a lei poderia ser usada para perseguir ações de protesto e reivindicações. ${ }^{19}$

Não iremos discutir aqui a questão da ineficácia de aumentar penas na tentativa de coibir certas condutas. Nossa proposta consiste em indagar quais riscos a lei antiterrorismo representa para a ação política no Brasil. Nesse sentido, duas críticas parecem ser centrais: a primeira diz respeito às definições vagas de ação terrorista que permitem assédio aos movimentos sociais e políticos; já a segunda, é relativa à interdição de busca de novos direitos.

A lei apresenta três critérios que caracterizam a ação terrorista: o fundamento da ação, o fim desejado e a forma praticada. Dentre estes critérios, os dois últimos são vagos e, por isso, permitem penalizar atos de contestação.

O fundamento é descrito como atos motivados por razões de xenofobia, discriminação e preconceito de raça, etnia, cor e religião. ${ }^{20} \mathrm{~A}$ finalidade é definida como o objetivo de "provocar o terror e expor a perigo a paz pública". A forma como está redigida este segundo critério é imprecisa na medida em que não fica claro o que significa colocar em perigo a paz pública. Além disso, este trecho do texto abre a possibilidade de punir alguém pela "intenção de provocar terror": basta que se tenha este propósito, não é preciso causar dano a nenhum patrimônio ou pessoa.

Os primeiros mandados de prisão com base na lei antiterrorismo - emitidos poucos dias antes do início das Olimpíadas, em julho de 2016 - foram baseados na intenção de causar terror. Os acusados haviam trocado algumas mensagens por meio da internet, não chegaram a atacar pessoas ou a destruir bens públicos ou privados. Além disso, eles não dispunham de armas ou outros meios para isso. ${ }^{21}$ Vale notar que, perseguir e penalizar pessoas com base em suas intenções - que dificilmente podem ser provadas - ao invés processar pessoas por atos, além de colocar em risco os fundamentos do direito, coloca em perigo a vida política, pois aproxima o regime vigente de práticas comumente mobilizadas por regimes ditatoriais e tirânicos.

O terceiro critério para caracterizar a ação terrorista, a forma praticada, também é vago. A descrição das formas é longa, contudo, não é bem definida. Por exemplo, a lei cita

19 Ver em http://www.conectas.org/pt/acoes/justica/noticia/41561-congresso-aprova-projeto-de-leiantiterrorismo, $\mathrm{e}$ em http://www.conectas.org/arquivos/editor/files/15-10-05\%20$\% 20$ Carta $\% 20$ aberta $\% 20 \% \mathrm{C} 3 \%$ A $0 \% 20$ Presidente $\% 20$ Dilma $\% 20$ Rousseff_FINAL.pdf

20 É importante notar que no projeto de lei assinado pelo ministro da justiça, o preconceito de gênero também integrava os fundamentos da ação terrorista. No entanto, na tramitação do Congresso este fundamento foi retirado do texto. No contexto atual, na África e no leste do Mediterrâneo uma das práticas comuns de grupos terrorista como Boko Haram e Estado Islâmico consiste no sequestro em massa de mulheres e meninas. Levando isso em conta, a retirada do preconceito de gênero como fundamento de ação terrorista mostra ou que os congressistas não possuem informações sobre o assunto ou que a lei não se refere mesmo ao terrorismo.

${ }^{21}$ Conferir em http://acervo.folha.uol.com.br/fsp/2016/07/22/20//6029535. 
o uso, porte ou transporte de conteúdos biológicos e químicos, mas não especifica quais danos estes conteúdos tem o potencial de causar. Em um país como o Brasil, em que recentemente pessoas foram detidas por carregar consigo vinagre e produtos de limpeza, esta imprecisão na lei antiterrorismo é, no mínimo, preocupante. ${ }^{22}$

Outro trecho impreciso se refere à descrição da prática de sabotar o funcionamento de serviços públicos - que não faz nenhuma ressalva quanto a greves e piquetes - e ao ato de tomar posse de instalações públicas - que não eximi manifestações políticas por meio de ocupações de ser qualificada como terrorismo.

Nesse sentido, ao deixar imprecisas a definição destas práticas, qualquer organização pode ser acusada de conduta terrorista. Além disso, na lei é afirmado que tais práticas não precisam ser a atividade principal de uma organização, elas podem ser secundárias e até mesmo ser de caráter eventual. Em outras palavras, a prática terrorista não é considerada algo sistemático e realizada por um grupo que tem como principal finalidade o terrorismo. Dessa forma, é notório que a lei abre a possibilidade de processar diversas organizações por terrorismo.

Estas definições vagas criam, por um lado, um problema jurídico e, por outro, um problema político. Juridicamente falando, os termos imprecisos dependem da doutrina e da jurisprudência para serem mais bem definidos, isto é, a interpretação será delimitada pelas futuras decisões do judiciário e pelos estudos na área do direito. Com as primeiras prisões com base nessa lei, a jurisprudência já começou a ser criada. Uma primeira observação que podemos fazer é que não foi preciso interligar os três critérios - fundamento da ação, finalidade e forma praticada - para iniciar um processo com base na lei antiterrorismo: um só elemento, a intenção de fazer um atentado, já foi suficiente. Como já foi mencionado, os mandados de prisão tiveram como prova o fato de que os acusados entraram na página eletrônica do Estado Islâmico e que conversaram pelas redes sociais sobre um possível atentado durante as olimpíadas.

Politicamente falando, os termos vagos da lei antiterrorismo podem produzir um discurso que legitima estratégias repressivas. Existem razões para temer as interpretações que o discurso político e a jurisprudência podem estabelecer, pois, no passado, durante a ditadura civil militar, o discurso de combate ao terrorismo foi usado para legitimar a perseguição política. E a despeito do trabalho da Comissão da Anistia e da Comissão da Verdade, o Brasil ainda não rompeu completamente com sua herança autoritária e violenta.

A prisão de quatro militantes do Movimento dos Trabalhadores Rurais sem Terra (MST) em agosto de 2016 confirma essa ameaça. Este foi o primeiro caso em que a justiça aceitou uma denúncia do Ministério Público de Goiás contra movimentos sociais que

${ }^{22}$ Ver em http://www.cartacapital.com.br/sociedade/morador-de-rua-e-condenado-a-5-anos-de-prisao-porcarregar-pinho-sol-e-agua-sanitaria-7182.html e em https://noticias.uol.com.br/cotidiano/ultimasnoticias/2013/06/13/jornalista-e-preso-durante-protesto-contra-aumento-da-tarifa-em-sp.htm 
apresentou uma associação da lei de organizações criminosas, 12.850 de 2013, com a lei antiterrorismo. Levando isso em consideração, vemos que esta última lei potencializou a capacidade do Estado de perseguir e penalizar manifestantes e movimentos políticos. ${ }^{23}$

A segunda crítica destinada à lei antiterrorismo consiste na interdição de busca de novos direitos. No segundo parágrafo da lei, encontramos uma ressalva que afirma que movimentos sociais, sindicais e políticos não devem ser enquadrados nas práticas terroristas se visarem a "defender direitos, garantias e liberdades constitucionais". As manifestações por novos direitos ou pela ampliação dos já existentes não são consideradas nesta ressalva. Nesse sentido, a lei antiterrorismo não prevê a reivindicação do novo, nem as ações que buscam mudança na vida pública. Ela reduz a liberdade de manifestação e de associação inscritas na Constituição na medida em que os atos políticos ficam restritos a defender o que já foi conquistado. Isto ameaça a luta por novos direitos.

Por mais legítimo que seja um governo eleito e o desenho institucional que ordena o sistema representativo - e este não parece ser o caso do Brasil - o governo não pode impossibilitar formas mais espontâneas e irregulares de intervenção política, nem a emergência de novas questões no espaço público. Por isso, Arendt no ensaio "Desobediência Civil" enfatiza que reprimir a contestação e as ações extra institucionais, significa tentar impedir a novidade na vida política. Em suas palavras: "A lei realmente pode estabilizar e legalizar uma mudança já ocorrida, mas a mudança em si é sempre resultado de ação extra-legal." Mais adiante a autora exemplifica sua afirmação: "Toda a substância da legislação trabalhista - o direito ao acordo salarial, o direito de se organizar e fazer greve - foi precedida por décadas de desobediência, às vezes violenta, às leis que no fim das contas se mostraram obsoletas". ${ }^{24}$

No pensamento de Arendt encontramos também a distinção entre contestação e resistência. Na perspectiva da autora, a contestação consiste no questionamento de um ato do governo ou de uma lei. Conforme foi mencionado acima, ela surge quando um grupo de pessoas desafia abertamente uma lei ou decisão do governo a fim de manter um estado de coisas ou criar um novo direito, mudar algo no mundo. Os contestadores, normalmente, são uma minoria organizada que se levanta contra um suposto consenso da maioria silenciosa, contra uma maioria que se encontra inarticulada. As minorias, no momento em que expressam publicamente sua divergência, podem incitar uma mudança no ânimo e na opinião da maioria e assim tornar sua reivindicação mais poderosa. ${ }^{25}$

Já a resistência é a ação que questiona a autoridade das instituições como um todo e o conjunto de leis. A resistência surge quando os governantes são considerados ilegítimos e

${ }^{23}$ Conferir em http://politica.estadao.com.br/noticias/geral,justica-mantem-sem-terra-presos-com-base-nalei-antiterrorismo, 10000066632

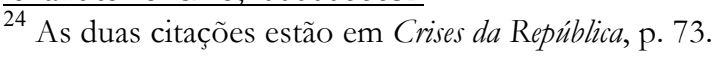

${ }_{25}$ Ver em Crises da República, p. 87. 
a forma constitucional inadequada. Arendt alerta que a contestação pode se tornar resistência quando as instituições e autoridades perdem apoio do povo, quando as manifestações públicas são desconsideradas e reprimidas a tal ponto que o senso de direitos e justiça da comunidade é violado.

Levando isso em conta, podemos dizer que se no Brasil o espaço de dissidência continuar a ser reduzido e os direitos e garantias fundamentais da Constituição continuarem a ser violados, o regime se tornará autoritário e ilegítimo e nesse contexto a desobediência civil pode e talvez devesse se tornar resistência.

\section{ANTI-TERRORISM LAW AND THE RESTRICTION OF POLITICAL ACTION: DISSENT AND RESISTANCE IN TIMES OF CRISIS OF THE REPUBLIC}

Abstract: This article aims at discussing the law number 13.260 of 2016, known as anti-terrorism legislation, taking into account Hannah Arendt's thought. Specifically, I pursue to think over the consequences of this law on public activities in Brazil through Arendtians concepts - such as, politics, action, civil disobedience, dissent, plurality and power.

Key words: Hannah Arendt - Politics - Dissent - Civil Disobedience - Rights.

\section{Referências Bibliográficas}

ARENDT, H. A condição humana. São Paulo: Forense Universitária, 2010.

Crises da República. São Paulo: Perspectiva, 2004.

Entre o Passado e o Futuro. São Paulo: Perspectiva, 2005.

Sobre a Revolução. São Paulo: Companhia das Letras, 2011.

Brasil. Ministério da Justiça. Projeto de Lei Antiterrorismo. Disponível em: http://www.camara.gov.br/proposicoesWeb/prop_mostrarintegra?codteor=1350712\&file name $=$ PL+2016/2015 Último acesso em: 17/02/2017.

Brasil. Presidência da República. Lei $\mathrm{n}^{\circ} 13.260$ de março de 2016. Disponível em: http://www.planalto.gov.br/ccivil_03/_ato2015-2018/2016/lei/113260.htm Último acesso em: 17/02/2017.

GARCIA, J. E CARVALHO, M. "Jornalista detido por portar vinagre em ato contra aumento da tarifa é liberado". UOL Notícias. São Paulo: 13/06/2013. Disponível em: https://noticias.uol.com.br/cotidiano/ultimas-noticias/2013/06/13/jornalista-e-presodurante-protesto-contra-aumento-da-tarifa-em-sp.htm. Último acesso em: 17/02/2017 
CONECTAS DIREITOS HUMANOS. "Congresso aprova projeto de lei entiterrorismo". Disponível em: http://www.conectas.org/pt/acoes/justica/noticia/41561-congressoaprova-projeto-de-lei-antiterrorismo

http://acervo.folha.uol.com.br/fsp/2016/07/22/20//6029535 Último acesso em: 17/02/2017.

CORREIA, A. Hannah Arendt e a Modernidade: politica, economia e a disputa por uma fronteira. Rio de Janeiro: Forense Universitária, 2014.

KALYVAS, A. Democracy and the Politics of the Extraordinary: Max Webber, Carl Schmitt and Hannah Arendt. Cambridge: Cambridge University Press, 2009.

LOCATELLI, P. "Morador de rua é condenado a 5 anos de prisão por carregar pinho sol e água sanitária". Carta Capital. São Paulo: 04/12/2013. Disponível em: http://www.cartacapital.com.br/sociedade/morador-de-rua-e-condenado-a-5-anos-deprisao-por-carregar-pinho-sol-e-agua-sanitaria-7182.html Último acesso em: 17/02/2017.

MASCARENHAS, G. "PF prende 10 brasileiros suspeitos de associação com o terrorismo". Jornal Folha de São Paulo. São Paulo: 22/07/2016. Disponível em: http://acervo.folha.uol.com.br/fsp/2016/07/22/20//6029535. Último acesso em: $\underline{16 / 02 / 2017 .}$

NEGRI, A. "Para onde vai o PT?”. Outras Paluras. São Paulo: 07/02/2017. Disponível em: http://outraspalavras.net/brasil/toni-negri-impressoes-de-uma-visita-ao-brasil/. Último acesso em: 15/02/2017.

NEVES, M. e Segalla, V. "Advogados são impedidos de ver presos suspeitos de preparar atos de terror". UOL Notícias. São Paulo: 24/07/2016. Disponível em: http://olimpiadas.uol.com.br/noticias/redacao/2016/07/23/advogados-sao-impedidosde-ver-presos-suspeitos-de-preparar-atos-de-terror.htm Último acesso em: 15/02/2017.

NOSSA, L. "Justiça mantém sem-terra presos com base na lei antiterrorismo". Jornal O Estado de São Paulo. São Paulo: 03/08/2016. Disponível em: http://politica.estadao.com.br/noticias/geral,justica-mantem-sem-terra-presos-com-basena-lei-antiterrorismo,10000066632. Último acesso em: 17/02/2017.

SANTIAGO, T. "Governo Alckmin libera reintegração de posse sem decisão judicial". Jornal O Estado de São Paulo. São Paulo: 13/05/2016. Disponível em: 
http://g1.globo.com/sao-paulo/noticia/2016/05/governo-alckmin-libera-reintegracao-deposse-sem-decisao-judicial.html. Último acesso em: 16/02/2017.

TELES, E. “Qual democracia?”. Blog da Boitempo. São Paulo: 18/03/2016. Disponível em: https://blogdaboitempo.com.br/2016/03/18/qual-democracia-2/_Último acesso em: 15/02/2017. 